LA-UR:- 94-318管 Conf-9410215--1

TITLE: SHOCK-WAVE BEHAVIOR IN EXPLOSIVE MONOCRYSTALS

AUTHOR(S): Jerry Joel Dick, DX-10

SUBMITTED To: Microscopic and Macroscopic Approaches to Detonation
Horkshop
St. Malo, France
October 1-8, 1994

DISCLAIMER

This report was prepared as an account of work sponsored by an agency of the United States Government. Neither the United States Government nor any agency thereof, nor any of their employees, makes any warranty, express or implied, or assumes any legal liability or responsibility for the accuracy, completeness, or usefulness of any information, apparatus, product, or process disclosed, or represents that its use would not infringe privately owned rights. Reference herein to any specific commercial product, process, or service by trade name, trademark, manufacturer, or otherwise does not necessarily constitute or imply its endorsement, recommendation, or favoring by the United States Government or any agency thereof. The views and opinions of authors expressed herein do not necessarily state or reflect those of the United States Government or any agency thereof.

By acceptance of this article, the publisher recognizes that the U.S. Government retains a nonexclusive, royalty-free license to publish or reproduce the published form of this contribution, or to allow others to do so, for U.S. Government purposes.

The Los Alamos National Laboratory requests that the publisher identify this article as work performed under the auspices of the U.S. Department of Energy.

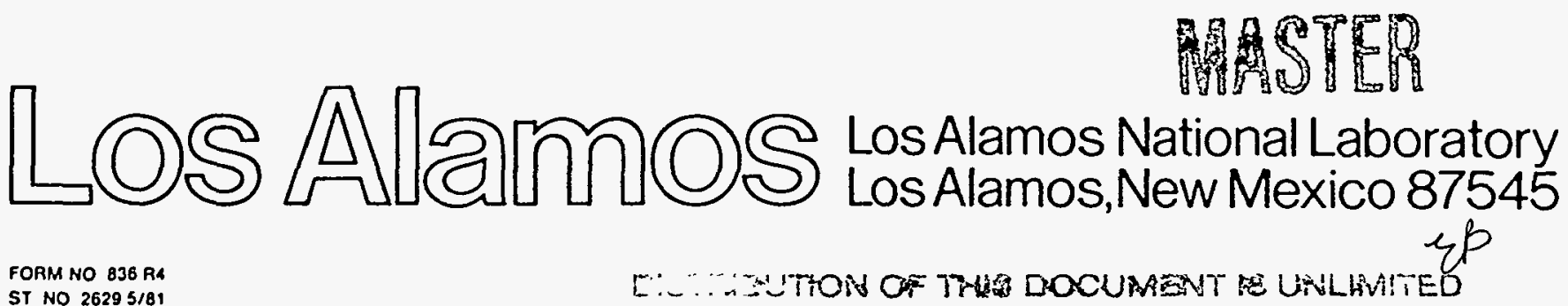




\section{DISCLAIMER}

Portions of this document may be illegible in electronic image products. Images are produced from the best available original document. 


\title{
Shock-wave behavior in explosive monocrystals
}

\author{
J. J. Dick \\ MS P952, Los Alamos National Laboratory, Los Alamos, New Mexico 87545 \\ $U S A$
}

(September 9, 1994)

\begin{abstract}
The shock response of explosive monocrystals is strongly anisotropic. Shock initiation sensitivity depends strongly on crystal orientation in PETN. This can be understood in terms of steric hindrance to shear during the shock-induced deformation of the molecular crystal. This initiation mechanism appears to be tribochemical rather than thermal.
\end{abstract}


In our work we have observed that the shock sensitivity for initiation of detonation depends strongly on the orientation of the crystal relative to the shock wave. ${ }^{1,2}$ This implies that the initiation process in monocrystals is not simply a bulk thermal process, since the shock-induced temperature increase should not depend strongly on orientation--It-must be controlled by some anisotropic crystal property. We have been able to explain our observations in terms of anisotropic shear flow in the uniaxial strain of a plane shock wave. The maximum resolved shear stress in a plane shock wave is at $45^{\circ}$ to the plane of the shock wave in a homogeneous material. In a crystal the shear flow will occur on a crystallographic plane near $45^{\circ}$. In molecular crystals the molecules are able to pass by each other without interference on some planes, but on other planes the molecules present obstacles to each other's passage in the shear flow. In pentrite (PETN) the $\mathrm{O}-\mathrm{NO}_{2}$ arms interfere with each other in some orientations. We have termed this effect steric hindrance to shear. We have found that orientations that have strong hindrance have high sensitivity especially at low stresses. The orientations with low hindrance are insensitive. No detonation has been observed in them up to $19 \mathrm{GPa}$ in crystals up to $10 \mathrm{~mm}$ thick.

We have studied four orientations. We have found [100] and [101] orientations to be insensitive and [110] and [001] to be sensitive by shock experiments and by steric hindrance analysis. An example of this orientation-dependent initiation sensitivity is shown in Fig. 1. Laser interferometer (VISAR) records for [100] (insensitive) and [001] (sensitive) orientations shocked to $4.18 \mathrm{GPa}$ are shown. The particle-velocity history for the [100] orientation shows a single wave to the final state. Behind the shock the particle velocity is essentiallyconstant as would be expected -for-inert behavior-- For the f001\} orientation-there is-a-double-wave structure. This is an elastic shock followed by a plastic or inelastic wave to the particle velocity of about $0.7 \mathrm{~mm} / \mu \mathrm{s}$. This elastic-plastic behavior is described in detail in Ref. 9 . Behind the plastic wave is a region of constantly increasing particle velocity. This is due to the exothermic decomposition in the initiation process for this sterically hindered case. Luminescent radiation has been observed from the sensitive orientations at this shock strength using image intensifier cameras, photodiodes, and spectrographs. Previous analysis indicates that this radiation is from excited electronic states of $\mathrm{NO}_{2}$ and possibly NO. ${ }^{1}$ Recent analysis indicates that the radiation begins at the base of the plastic wave. This coincides with the onset of the sterically hindered shear and suggests that the first endothermic step in initiation in explosive monocrystals may be tribochemical owing to bond breaking by the sterically hindered shear process.

This orientation-dependent sensitivity has been corroborated by L. Soulard. ${ }^{3}$ He studied [111] and [001] orientations of PETN with PVDF gauges at shock strengths from 5 to 11 $\mathrm{GPa}$. His results show considerable more reactivity for the [001] orientation than for the [111] orientation.

Rudel and coworkers have studied the orientation dependence of the efficacy for detonation in PETN and nitromethane. ${ }^{4}$ They described the efficacy in terms of the lateral stiffness of NO chains in the crystal. It is interesting that they found efficacy in the same orientations that we found to sensitive to initiation in these explosives. ${ }^{1,5}$

At low stresses we have found anomalous sensitivity in that the run distance to detonation is shorter at $4.2 \mathrm{GPa}$ than at $8.5 \mathrm{GPa}$ for the [110] orientation. By studying the induction time for the onset of emission, D. Spitzer has shown the this anomalous sensitivity is strongest at about $5 \mathrm{GPa}^{6}$ We undertook a series of VISAR laser interferometer experi- 
ments at $4.2 \mathrm{GPa}$ in order to try to understand the basis for this anomaly. They displayed an elastic-plastic, two-wave structure. The anomaly is apparently associated with this structure. Our tentative conclusion is that the prestrain generated by the elastic wave makes the sterically hindered shear even more effective in causing explosive initiation chemistry.

M. Samirant has reported detonation velocities for PETN for [100] and [001] orientations. ${ }^{7}$ The $[100]$ orientation is one for which no sign of intitiation has been observed in our experiments to $19 \mathrm{GPa}$. The experiments include wedge, VISAR, and image-intensifier camera types. In Samirant's experiments the PETN crystals were initiated by detonating explosive in contact. This implies an input shock strength of about $30 \mathrm{GPa}$. It seems reasonable that even the insensitive, hindered orientations will detonate if shocked at detonation pressure.

In order to confirm this we have performed some exploratory experiments of mass spectrometry of reaction products of initiating and detonating PETN crystals with N. R. Greiner. ${ }^{8}$ Complete mass spectra are obtained at $12 \mu$ s intervals in the vacuum chamber. PETN crystals of hindered, sensitive [110] and unhindered, insensitive [101] orientations were subjected to pressures of 18 and $30 \mathrm{GPa}$ using $1.65 \mathrm{~g} / \mathrm{cm}^{3} \mathrm{HMX}$ and $1.55 \mathrm{~g} / \mathrm{cm}^{3}$ TATB, respectivly, in contact. Two experiments were performed at each pressure with each orientation. The results were not completely reproducible, but the spectra are indicative of final detonation products at $30 \mathrm{GPa}$ for both orientations. At late times there is evidence of undecomposed PETN for the [101] orientation. At $18 \mathrm{GPa}$ for [110] orientation there is early evidence of final detonation products and some unreacted PETN signal at later times. For [101] there are some weak signals of early decomposition products along with unreacted PETN signal at later times. Overall, the results corroborate the results stated in the previous paragraph that all orientations detonate when subjected to detonation pressures even though the initiation sensitivity varies greatly at lower pressures.

The question remains as to whether the the first endothermic, bond-scission step is a tribochemical one or due to local molecular thermal excitation by the steric hindrance in terms of phonon-vibron up-pumping. In Fig. 2 are shown radiance spectral data for the two sensitive orientations shocked to about $4.2 \mathrm{GPa}$. Grey body curves from Planck's law are also shown. The temperatures were chosen so that the curves had peak radiance at about the same wavelength as the radiance data from the shock experiment. The emissivity constants were chosen to match the experimental peak radiance. The temperatures of 5000 and $6000 \mathrm{~K}$ are unreasonably high and the experimental data have a different form than that given by Planck's law for a black or grey body. This can be interpreted as more evidence the radiation observed is luminescence from excited electronic states, not thermal radiation. The timing of the luminescence coinciding with the beginning of the plastic wave and shear flow suggests that it may be due to a tribochemical process, (i.e., a mechanical process analagous to friction caused by the stericaly hindered shear flow). The molecules become obstacles to one another and are not able to deform enough to pass by in the time scale involved. ${ }^{9}$

Subsequent processes in the exothermic buildup to detonation may likely be occurring in localized regions of the crystal, perhaps in slip bands. This concentrates the shock energy and subsequent heat release in a small fraction of the crystal during the initial phase of initiation. This failure mechanism under shock conditions may be similar to that observed by Ananin and coworkers ${ }^{10}$ in crystalline quartz, a material with similar mechanical properties. 


\section{REFERENCES}

* This work was performed under the auspices of the U. S. Department of Energy and partially supported by the Office of Munitions Memo of Understanding between the Department of Energy and the Department of Defense.

${ }^{1}$ J. J. Dick, R. N. Mulford, W. J. Spencer, D. R. Pettit, E. Garcia, and D. C. Shaw, J. Appl. Phys. 70, 3572 (1991).

2 J. J. Dick, Appl. Phys. Lett. 44, 859 (1984).

${ }^{3}$ L. Soulard, thesis, "Etude du Monocristal de Pentrite Soumis a un Choc Plan," L'Universite de Haute-Alsace, 1990; L. Soulard and F. Bauer, in Shock Compression of Condensed Matter-1989, edited by S. C. Schmidt, J. N. Johnson, and L. W. Davison (Elsevier, Amsterdam, 1990),p. 817.

${ }^{4}$ P. Rudel, S. Odiot, J. C. Mutin, J. C. Peyrard, J. Chim. Phys. 87, 1307 (1990).

${ }^{5}$ J. J. Dick, J. Phys. Chem. 97, 6193 (1993).

${ }^{6}$ D. Spitzer, thesis, "Etude du Role des Defauts de Taille Microscopique dans la Transition Choc-Detonation du Monocristal de Pentrite," Universite Louis Pasteur de Strasbourg, p. 153, 1993.

${ }^{7}$ M. Samirant, J. Phys. (Paris) 48, C4-85 (1987).

${ }^{8}$ N. R. Greiner and N. C. Blais, Ninth Symposium (International) on Detonation, (Office of Naval Research, Arlington, VA, 1989), p. 953. also N. C. Blais, H. A. Fry, and N. R. Greiner, Rev. Sci. Instrum. 64, 174 (1993) and in Tenth Symposium (International) on Detonation, in press.

${ }^{9}$ J. J. Dick and J. P. Ritchie, J. Appl. Phys. 76, 2726 (1994).

${ }^{10}$ A. V. Ananin, O. N. Breusov, A. N. Dremin, S. V. Pershin, and V. F. Tatsii, Fiz. Goreniya Vzryva, 10, 426 (1974). 


\section{FIGURES}

FIG. 1. Particle vs time histories at the PETN/PMMA interface for [100] and [001] orientation crystals shocked to an input stress of $4.18 \mathrm{GPa}$. The [100] record begins at $0.790 \mu \mathrm{s}$ and the [001] record begins at $0.988 \mu \mathrm{s}$.

FIG. 2. Emission spectra of [110] and [001] orientations of PETN shocked to $4.2 \mathrm{GPa}$. Shock position is 1.8 to $2.4 \mathrm{~mm}$ during the acquisition of the data. The dashed lines represent grey-body curves from Planck's law. For [110] the grey-body temperature is $5000 \mathrm{~K}$ and the emissivity is 0.0042. For [001] the temperature is $6000 \mathrm{~K}$ and the emissivity is 0.0009 . 


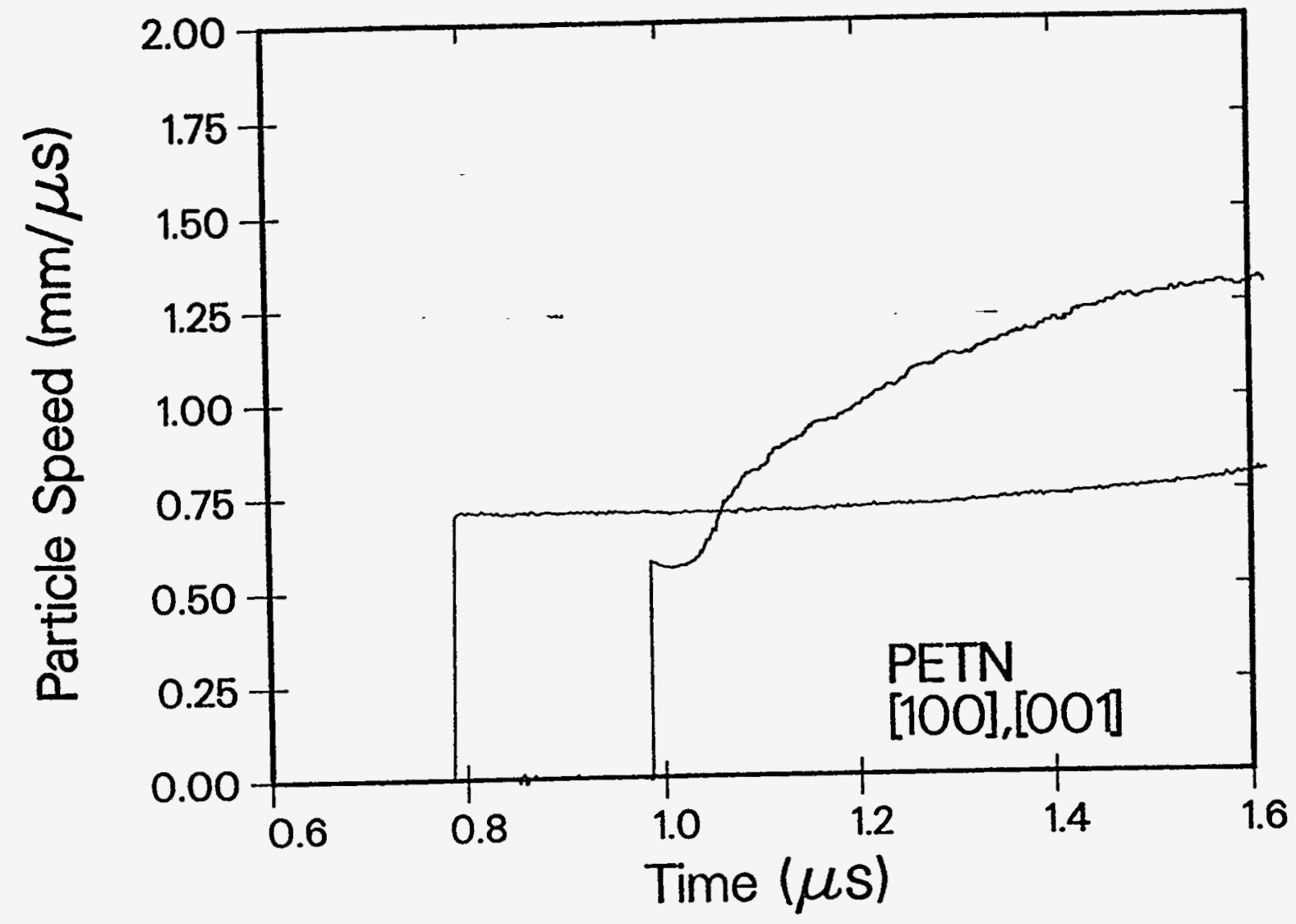

Flgure 1 


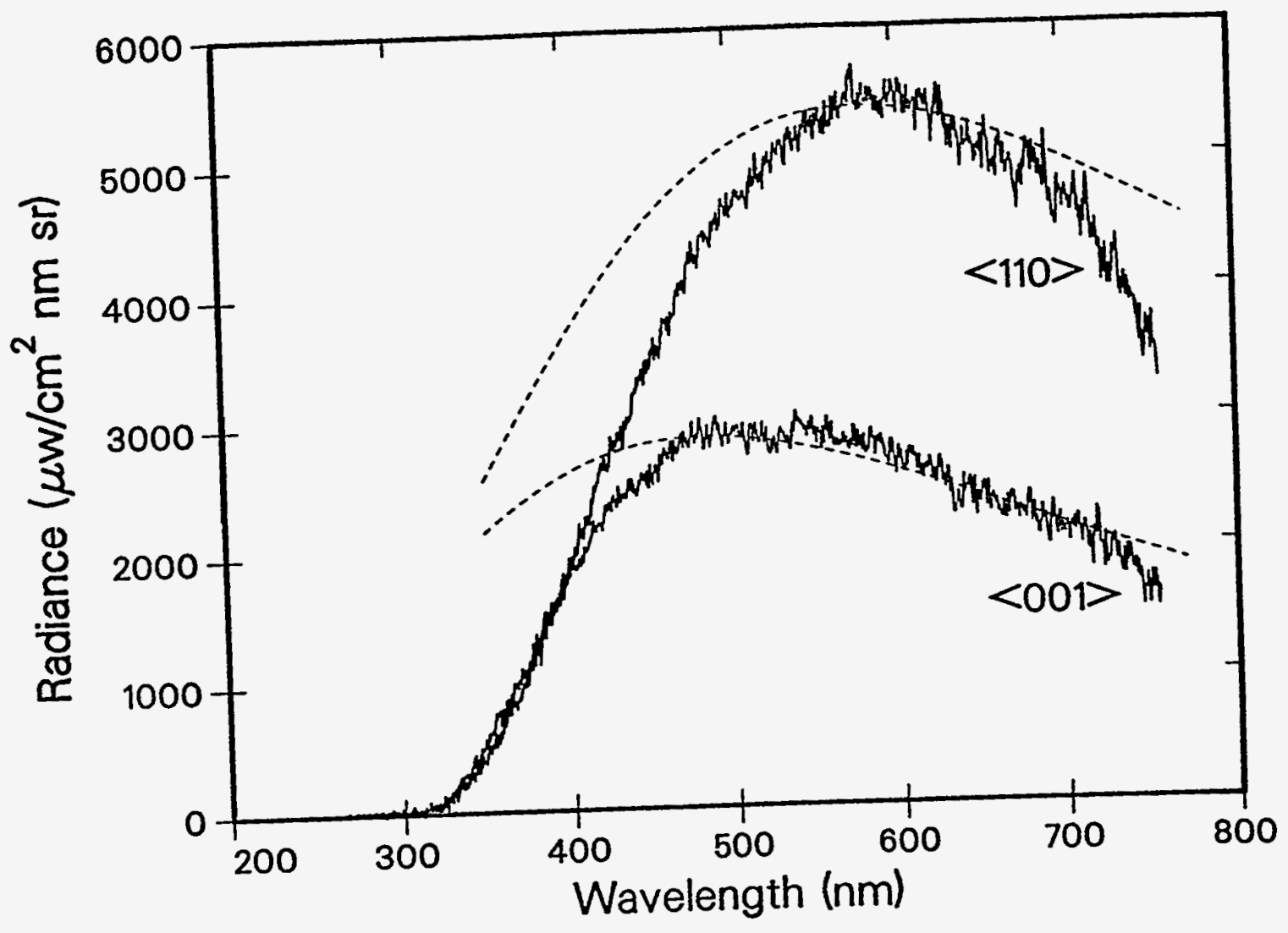

Figure 2 